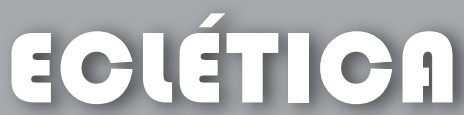 química
}

\section{DEVELOPMENT AND VALIDATION OF SPECTROPHOTOMETRIC METHOD FOR THE DETERMINATION OF DPP-4 INHIBITOR, SITAGLIPTIN, IN ITS PHARMACEUTICAL PREPARATIONS}

\author{
C. Bala Sekaran ${ }^{1 *}$, A. Prameela Rani ${ }^{2}$ \\ ${ }^{1}$ Department of Biotechnology, J. K. C. College, Guntur, India. ${ }^{2}$ Department of Pharmaceutics, K.V.S.R. Siddhartha College of \\ Pharmaceutical Sciences, Vijayawada, India. \\ * Corresponding Author: C. Bala Sekaran, 20-3/2-5, II Floor, Ramalayam Street, \\ Ayodhya nagar, Vijayawada-520 003. Andhra Pradesh. \\ E-Mail: balumphil@gmail.com \\ Call: 91-866-2538492
}

\begin{abstract}
A simple, sensitive and reproducible spectrophotometric method was developed for the determination of sitagliptin phosphate in bulk and in pharmaceutical formulations. The proposed method is based on condensation of the primary amino group of sitagliptin phosphate with acetyl acetone and formaldehyde producing a yellow colored product, which is measured spectrophotometrically at 430nm. The color was stable for about 1 hour. Beer's law is obeyed over a concentration range of $5-25 \mu \mathrm{g} / \mathrm{ml}$. The apparent molar absorptivity and Sandell sensitivity values are $1.067 \times 10^{4} \mathrm{Lmol}^{-1} \mathrm{~cm}^{-1}$ and $0.0471 \mu \mathrm{gcm}^{-2}$ respectively. All the variables were studied to optimize the reaction conditions. No interference was observed in the presence of common pharmaceutical excipients. The validity of the method was tested by analyzing sitagliptin phosphate in its pharmaceutical preparations. Good recoveries were obtained. The developed method was successfully employed for the determination of sitagliptin phosphate in various pharmaceutical preparations.
\end{abstract}

Keywords: Sitagliptin phosphate, Acetyl acetone, Beer's Law, Sandell's sensitivity.

\section{INTRODUCTION}

Sitagliptin phosphate(STP)(1-4) is 1,2,4-triazolo[4,3-a]pyrazine,7-[(3R)-3-amino-1-oxo-4-(2,4,5-trifluorophenyl)butyl]-5,6,7,8-tetrahydro-3-(trifluoromethyl)-, phosphate, whose structure is given in the Fig. 1. It is used in the treatment of diabetes. It is an oral antihyperglycemic (anti-diabetic) drug of the dipeptidyl peptidase-4 (DPP-4) inhibitor class. Literature survey reveals that only LC-MS (5-8) methods were reported for the determination of sitagliptin phosphate in plasma and urine of humans, rats and dogs. So far, no assay procedure has been reported for the determination of this drug in its pharmaceutical formulations. Among the various methods available for the determination of drugs, spectrophotometry continues to be very popular, because of their simplicity, specificity and low cost. This study presents new spectrophotometric method for the determination of sitagliptin phosphate in bulk and pharmaceutical formulations. The developed method is based on the reaction of sitagliptin phosphate with acetyl acetone and formaldehyde producing Hantzsch product. 


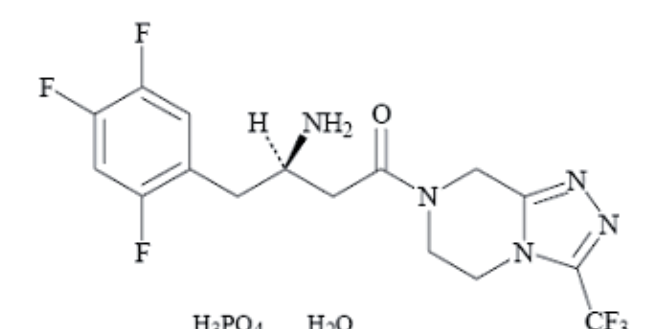

EXPERIMENTAL

\section{Apparatus}

- Spectral and absorbance measurements were carried out by using Systronics UV - Visible Double beam spectrophotometer model 2201.

- Systronics digital $\mathrm{pH}$ meter was used to adjust and determine the hydrogen ion concentration $(\mathrm{pH})$ of the buffer solution.

Materials and Reagents: All the chemicals used were of analytical grade. All the solutions were freshly prepared in distilled water.

- Acetylacetone: $8.4 \% \quad \mathrm{v} / \mathrm{v}$ solution was freshly prepared by mixing $2.1 \mathrm{ml}$ of acetyl acetone with $10 \mathrm{ml}$ of acetate buffer $(\mathrm{pH} 5)$ and diluted to $25 \mathrm{ml}$ with distilled water.

- Formaldehyde (34 - 40\%): Twenty percent solution was prepared by mixing $5 \mathrm{ml}$ of formaldehyde with $10 \mathrm{ml}$ of acetate buffer ( $\mathrm{pH} 5)$ and diluted to $25 \mathrm{ml}$ with distilled water.

- Acetate buffer (pH 5): Prepared by dissolving $13.6 \mathrm{~g}$ of sodium acetate and $6 \mathrm{ml}$ of glacial acetic acid in sufficient water to produce $1000 \mathrm{ml}$.

- Pharmaceutical grade Sitagliptin phospha-

te, certified to be $99.8 \%$ pure was procured from local pharmaceutical industry and was used as received.

- Januvia $100 \mathrm{mg}, 50 \mathrm{mg}$ and $25 \mathrm{mg}$ (labeled to contain $100 \mathrm{mg} 50 \mathrm{mg}$ and $25 \mathrm{mg}$ of sitagliptin phosphate pe phosphate per tablet) were obtained from the local pharmacy.

\section{Standard drug solution}

Stock solution of STP $(1 \mathrm{mg} / \mathrm{ml})$ was prepared by dissolving $100 \mathrm{mg}$ of STP in distilled water and making the volume to $100 \mathrm{ml}$ in a standard volumetric flask. Working solution of lower concentration $(100 \mu \mathrm{g} / \mathrm{ml})$ was prepared by further dilution of the above standard stock solution with water.

\section{General procedure for the determination of Sita-}

Different aliquots of working standard solutions containing 50-250 $\mu \mathrm{g}$ of STP was transferred into a series of serially numbered $10 \mathrm{ml}$ volumetric flasks. To each flask $1 \mathrm{ml}$ of $8.4 \% \mathrm{v} / \mathrm{v}$ acetyl acetone solution and $0.5 \mathrm{ml}$ of $20 \%$ formaldehyde reagents were added. The flasks were stoppered, contents were mixed well. The mixture was heated for $5 \mathrm{~min}$, cooled and diluted to $10 \mathrm{ml}$ with distilled water. The absorbance of the yellow color solution was measured at $430 \mathrm{~nm}$ using the experiment as a blank. The amount of sitagliptin phosphate present in the sample was computed from the corresponding calibration curve.

The calibration graph was prepared was prepared by plotting absorbance versus concentration of drug and the concentration of the unknown was read from the calibration graph or computed from the regression equation derived from the Beer's law data. The calibration graph was then prepared by plotting the absorbance versus concentration of the drug

\section{Assay procedure for pharmaceutical tablets}

For the analysis of STP, three brands of commercially available tablets (20) were weighed gliptin phosphate

and ground into a fine powder. An accurately weighed portion of the powder equivalent to $100 \mathrm{mg}$ of sitagliptin phosphate was transferred in to a $100 \mathrm{~m}$ beaker containing small volume of water and the solution was shaken thoroughly for 10-15 minutes and filtered through a whatman filter paper no.1 to remove the insoluble matter. The filter paper was washed with water and the washings were adde to the filtrate, the final volume $(100 \mathrm{ml})$ was made with water. A suitable aliquot of this solution in the working range of sitagliptin phosphate was treated as per procedure described in the above determination of pure sitagliptin phosphate. The nominal content of STP in the tablets was calculated either from a previously plotted calibration graph or using the regression equation

Fig 2. Tentative reaction scheme for the formation of Hantzch product

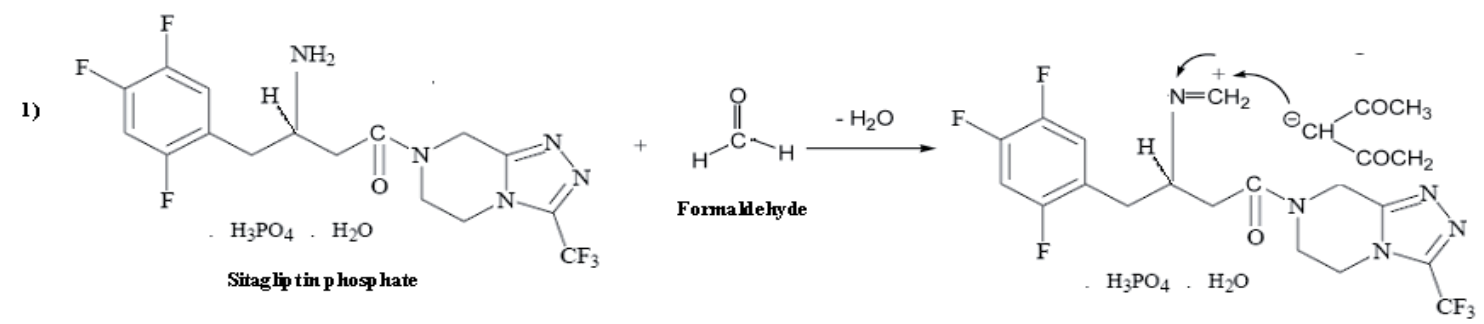

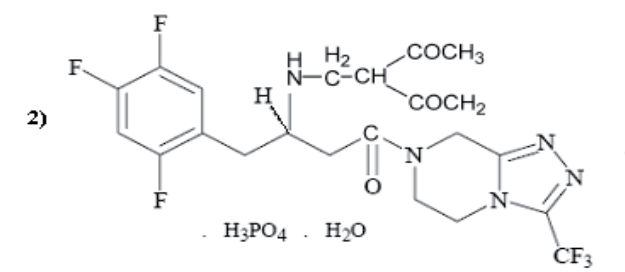

Chemistry of the colored species

Hantzsch reaction is a known condensation reaction that was reported in the literatures as a useful pathway for pyrrole and pyridine synthesis (9). In the same manner, acetylacetone together with formaldehyde react with aliphatic amines by Hantzsch reaction forming a yellow product that can be measured spectrophotometrically or spectrofluorimetrically. This reaction was applied for the determination of certain sulpha-Drug (10), ka-
Determination of Absorption Maxima was added to $10 \mathrm{ml}$ volumetric flask. Then $1 \mathrm{ml}$ of $8.4 \% \mathrm{v} / \mathrm{v}$ acetyl acetone solution and $0.5 \mathrm{ml}$ of $20 \%$ formaldehyde reagents were added. The contents were mixed well. The mixture was heated for $5 \mathrm{~min}$, cooled and diluted to $10 \mathrm{ml}$ with distilled water. The absorbance was measured against reagent blank in the range of $400-700 \mathrm{~nm} . \lambda$ for STP was found to be $430 \mathrm{~nm}$. Absorption spectrum of the proposed method was shown in Fig. 2 . Under the experimental conditions each reagen blank showed a negligible absorbance at the corresponding $\lambda_{\text {max }}$

\section{RESULTS AND DISCUSSION} $\left(\lambda_{\mathrm{ma}}\right)$ : To determine the $\lambda \quad 10 \mu \mathrm{g} / \mathrm{ml}$ of the STP namycin (11), lisinopril (12) and gabapentin and prozil (13)

The proposed method for determination of STP (primary amine compound) was based on Hantzsch condensation reaction using acetylacetone as $\beta$-diketone and formaldehyde as an aldehyde to form a colored condensation product. The formed yellow color showed maximum absorption at $430 \mathrm{~nm}$ (Fig. 3). The probable reac(14) is given in Fig.2 


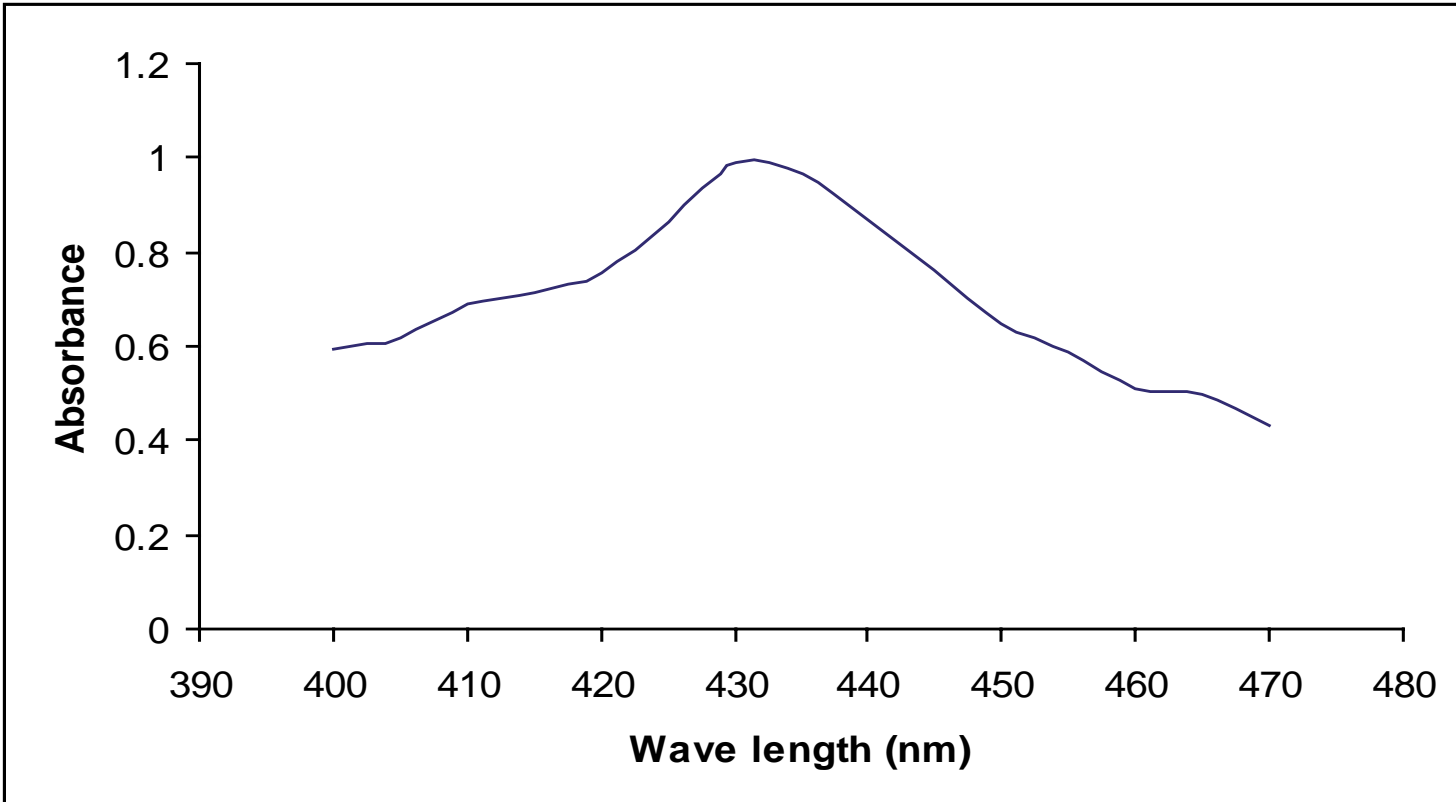

\section{Investigation of Assay Parameters}

Optimum reagent concentrations required for the formation of sensitive and quantitative colored products were determined by varying one reagent concentration and fixing the concentrations of other reagents and its effect on absorbance was measured at $430 \mathrm{~nm}$.

\section{Effect of heating time:}

To study the effect of heating time for the development of maximum color, the contents of the mixture were heated for up to $30 \mathrm{~min}$ at 100 $\pm 1^{\circ} \mathrm{C}$. The intensity of the color developed was measured at room temperature $\left(25 \pm 1^{\circ} \mathrm{C}\right)$ after dilution to $10.0 \mathrm{ml}$ with double distilled water. It is apparent from this investigation that the maximum intensity of color was obtained after 5 min of heating and remained constant up to $30 \mathrm{~min}$. Therefore, the optimum heating time was fixed at 5 min.

Different diluting solvents were used, such as water, ethanol, methanol, acetonitrile and ace- tone. Best color intensities were obtained using the first three solvents; water was used, being the most available solvent.

\section{Interference Studies}

To study the potential interference from the commonly used excipients and other adrot the commonly used ch glycolate, cellulose, magnesium stearate and Table 1. Determination of STP in the Presence of Excipients

\begin{tabular}{ccccc}
\hline S.No. & Excipients & Amount taken $(25 \mu \mathrm{g} / \mathrm{ml})$ & $\begin{array}{c}\text { Recovery } \\
(\%)\end{array}$ & RSD (\%) (n= 5) \\
\hline 1 & Cellulose & 300 & 99.8 & 0.26 \\
2 & Glucose & 50 & 99.6 & 0.15 \\
3 & Lactose & 300 & 99.4 & 0.36 \\
4 & Starch & 200 & 100.2 & 0.42 \\
5 & Sodium starch glycolate & 100 & 99.8 & 0.28 \\
6 & Magnesium stearate & 50 & 99.5 & 0.37 \\
7 & Ascorbic acid & 50 & 100.1 & 0.46 \\
\hline
\end{tabular}

\section{Validation of the method:}

Detection and Quantification Limits: According to the Analytical Methods Committee(15) the detection limit (LOD) is the concentration of drug corresponding to a signal equal to the blank mean $\left(\mathrm{Y}_{\mathrm{B}}\right)$ plus three times the standard deviation of the blank $\left(\mathrm{S}_{\mathrm{B}}\right)$. Quantification limit $(\mathrm{LOQ})$ is the concentration of drug corresponding to the blank mean plus ten times the standard deviation of the cank. The LOD and LOQ values for STP we blannd to be 1.947 and $5.90 \mu$ values for STP wer found to be 1.947 and $5.90 \mu \mathrm{g} / \mathrm{ml}$ respectively.

Quantification: The optical characteristics such as Beer's law limits (Fig: 4), Sandell's sensitivity and molar absorptivity were calculated for the proposed method and the results are summarized in Table 2. Regression analysis of the Beer's law plot at their $\lambda_{\max }$ revealed a good correlation. Graphs of absorbance versus concentration showed zero intercept and are described by the regression equation absorbance, $\mathbf{b}$ is the slope, $\mathbf{x}$ is the concentration ascorbic acid, recovery studies were carried out. Under the experimental conditions employed, to a known amount of drug (sitagliptin phosphate $25 \mu \mathrm{g} / \mathrm{ml}$ ), excipients in different concentrations were added and analyzed. Results of the recovery analysis are presented in Table 1. Excipients at the concentrations shown in Table 1 do not interfere with the assay. In addition recoveries in most cases were around $100 \%$ and the lower relative standard deviation (RSD) values indicate the good precision of the proposed method. rized in Table 2. of drug in $\mu \mathrm{g} / \mathrm{ml}$ and $\mathrm{a}$ is the intercept) obtained by least squares method. The results were summa- 
Fig 4. Linearity of absorbance to concentration of Hantzch product

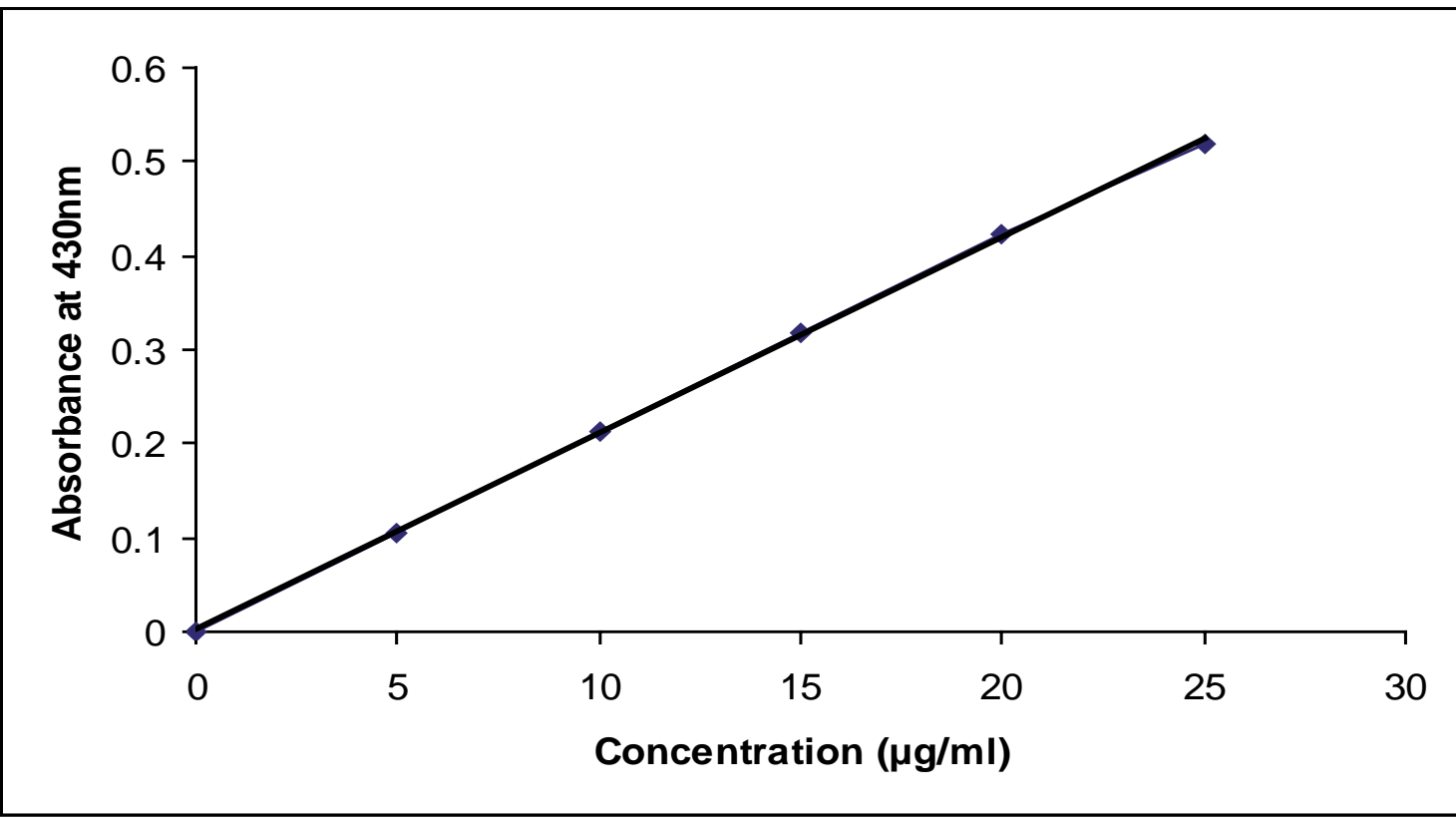

Table 2. Optical and Regression characteristics, Precision and Accuracy of the proposed method

\begin{tabular}{cc}
\hline Parameters & Method B \\
\hline$\lambda_{\text {max }}(\mathrm{nm})$ & 430 \\
Beer's law limit $(\mu \mathrm{g} / \mathrm{ml})$ & $5-25$ \\
Sandell's Sensitivity $\left(\mu \mathrm{g} / \mathrm{cm}^{2} / 0.001\right.$ abs. unit) & 0.0471 \\
Molar absorptivity $\left(\right.$ Litre.mole $\left.^{-1} \cdot \mathrm{cm}^{-1}\right)$ & $1.067 \times 10^{4}$ \\
Stability of Color (hours) & 1 \\
Regression equation $(\mathrm{Y})^{*}$ & \\
Intercept (c) & 0.0106 \\
Slope(b) & 0.0020 \\
Correlation coefficient & 0.9998 \\
\% Relative standard deviation ${ }^{* *}$ & 1.13 \\
\% Range of errors & \\
0.05\% level & 0.951 \\
0.01\% level & 1.397 \\
Limit of detection $(\mu \mathrm{g} / \mathrm{ml})$ & 1.947 \\
Limit of quantification $(\mu \mathrm{g} / \mathrm{ml})$ & 5.90 \\
\hline
\end{tabular}

$* \mathrm{Y}=\mathrm{c}+\mathrm{bx}$, where $\mathrm{Y}$ is the absorbance and $\mathrm{x}$ is the concentration of Sitagliptin phosphate in $\mu \mathrm{g} / \mathrm{ml}$ ** Average of six determinants
Accuracy precision and recovery studies: The accuracy and precision of the proposed method was evaluated by performing five replicate determinations of STP in pure form at three different concentrations (5,10 and $15 \mu \mathrm{g} / \mathrm{ml}$ ) by short term (intra day) and daily (inter day) precisions (Table 3). The standard analytical errors, relative standard deviations (RSD) and recoveries obtained in the intra day and inter day andysis for the proposed method was found to be acceptate. Thus the proposed method is effective for the determination of STP.

Table 3. Evaluation of the accuracy and precision of the proposed method by Intra day and Inter day assay

\begin{tabular}{|c|c|c|c|c|c|c|c|c|}
\hline \multirow{3}{*}{$\begin{array}{c}\text { Concentration } \\
\text { of sitagliptin } \\
\text { phosphate( }(\mu \mathrm{g} / \mathrm{ml})\end{array}$} & \multicolumn{8}{|c|}{ Observed Concentration of STP $(\mu \mathrm{g} / \mathrm{ml})$} \\
\hline & \multicolumn{4}{|c|}{ Intra-day } & \multicolumn{4}{|c|}{ Inter-day } \\
\hline & Mean $^{*}$ & Error (\%) & RSD (\%) & Recovery (\%) & Mean & Error (\%) & RSD (\%) & Recovery (\%) \\
\hline 5 & 4.97 & 0.60 & 0.56 & 99.40 & 5.02 & 0.40 & 0.48 & 100.4 \\
\hline 10 & 10.10 & 1.00 & 0.39 & 101.00 & 9.98 & 0.20 & 0.19 & 99.80 \\
\hline 15 & 15.06 & 0.40 & 0.43 & 100.40 & 14.97 & 0.20 & 0.73 & 99.80 \\
\hline
\end{tabular}

* For five determinants

The accuracy of the proposed method was further checked by performing recovery experiments through standard addition technique. For this purpose, a known amount of pure STP was added to pre-analyzed dosage forms and then determined by the recommended procedure. The results (Table 4) shown that the mean recovery and relative standard deviation (RSD) were in the range of 99.94-100.12 and $0.26-0.54 \%$ indicating the reproducibility of the method. No interference from the common excipients was observed.

Table 4. Determination of STP in pharmaceutical formulations by standard addition technique

\begin{tabular}{ccccc}
\hline $\begin{array}{c}\text { Amount of drug } \\
\text { added }(\mu \mathrm{g})\end{array}$ & $\begin{array}{c}\text { Theoretical } \\
\text { amount }(\mu \mathrm{g})\end{array}$ & $\begin{array}{c}\text { Mean amount }(\mu \mathrm{g}) \\
\text { Recovered(n=5) }\end{array}$ & $\begin{array}{c}\text { Mean \% of } \\
\text { Recovery }(\mathrm{n}=5)\end{array}$ & RSD (\%) \\
\hline 50 & 50 & 100.12 & 100.12 & 0.26 \\
100 & 100 & 199.89 & 99.94 & 0.54 \\
\hline
\end{tabular}

\section{ANALYSIS OF PHARMACEUTICAL PREPARATIONS}

The proposed methods were applied to the analysis of STP in pharmaceutical dosage forms and the results were statistically compared with UV method by calculating the Student's t- and F-values. The evaluated t- and F-values were less than the tabulated values at the $95 \%$ confidence level for eight degrees of freedom (16), as revealed by the results complied in Table 5. This actually suggests that the proposed methods are accurate and precise as the UV method. 
Table 5. Results of analysis of tablet formulations containing STP

\begin{tabular}{cccccc}
\hline \multirow{2}{*}{ Formulations } & $\begin{array}{c}\text { Labeled } \\
\text { amount(mg) }\end{array}$ & $\begin{array}{c}\text { Reference } \\
\text { method }^{*}\end{array}$ & $\begin{array}{c}\text { Proposed } \\
\text { method }\end{array}$ & t-test & F-test \\
\hline Tablet I & 100 & $99.83 \pm 0.24$ & 99.94 & 2.01 & 5.01 \\
Tablet II & 50 & $100.16 \pm 0.56$ & 98.82 & 1.58 & 4.25 \\
Tablet III & 25 & $99.83 \pm 0.24$ & 99.93 & 1.56 & 3.45 \\
\hline
\end{tabular}

** Recovery amount was the average of five determinants

* UV method developed in the laboratory

Tabulated t-value at $95 \%$ confidence level is 2.306

Tabulated F-value at $95 \%$ confidence level

\section{CONCLUSIONS}

The proposed method was quite simple and do not require any pretreatment of the drug and tedious extraction procedure. The methods have wider linear range with good accuracy and precision. Hence, the data presented in the manuscript "Development and validation of a spectrophotometric method for the determination of a DPP-4 inhibitor sitagliptin, in its pharmaceutical preparations" demonstrate that the proposed method par accurate, precise, linear, selective and offer was accures advantages of reagent availability and stability, less time consumption and high sensitivity. Thus it can be extended for routine analysis of STP in pharmaceutical industries, hospitals and research laboratories. Unlike the LC/MS procedure and high performance liquid chromatography procedures, the UV-visible spectrophotometer instrument is simple and not of high cost, on the other hand in terms of simplicity and expense, the meorted methods. Moreover from interferences by common additives and excipients.

\section{ACKNOWLEDGEMENTS}

The authors are grateful to the Management of J.K.C College, Guntur and Management of Siddhartha Academy, Vijayawada for their con- tinuous support and encouragement for providing the necessary facilities. Yi B, M. De Smet, K. Snyder, D. Hilliard, M. Tanen, W. Tanaka, A. Wang. W. Zeng, D. Musson, G. Winchell, M. Davies, S. Ramael, K. Gottesdiener and J. Wagner, Clinical Pharmacology and Therapeutics. 78(6) (2005) 675.

2] Januvia Side Effects \& Drug Interactions. RxList. com, 2007.

[3] U.S. Food and Drug Administration. FDA Approves New Treatment for Diabetes. 2006.

4] G. Herman, A. Bergman, F. Liu, C. Stevens, A Wang, W. Zeng, L. Chen, K. Snyder, D. Hilliard, M. Tanen, W. Tanaka, A. Meehan, K. Lasseter, S. Dilzer, R. Blum and J. Wagner. Journal of Clinical Pharmacology. 46(8) (2006) 876

5] H. Stella Vincent, R. James Reed, A. J. Bergman, C. S. Elmore, Bing Zhu, Shiyao Xu, David Ebel, Patrick Lasseter, Keith Gottesdiener, J. A. Wagner and G. A. Herman. Drug Metabolism and Disposition. 35(4) (2007) 533.

6] Wei Zeng, Donald G Musson, Alison L Fisher, Li Chen, Michael S Schwartz, Eric J Woolf and Amy Qiu Wang. Journal of Pharmaceutical and Biomedical Analysis. 2008, 46(3) (2008) 534

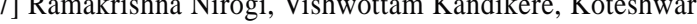
Mudigonda, Prashanth Komarneni, Raghupathi Aleti, Rajeshkumar Boggavarapu. Biomedical Chromatography 22(2) (2008) 214

\section{REFERENCES}

11] G. Herman, C. Stevens, K. Van Dyck, A. Bergman, Larson, Wei Zeng, Li Chen, Stacy Dilzer, Kenneth
[8] M. G. Beconi, J. R. Reed, Yohannes Teffera, YuanQing Xia, C. J. Kochansky, D. Q. Liu, Shiyao Xu, C. S. Elmore, Suzanne Ciccotto, D. F. Hora, R. A. Stearns, and S. H. Vincent. Drug Metabolism and Disposition. $35(4)(2007) 525$.

[9] F. R. S Derker Bratlon and W. David Olis. Comprehensive Organic Chemistry, The Synthesis and Reactions of Organic Compounds. 4, Pergamon Press, London, 65, 1979, pp. 298. [10] A. S. Amin and M. M. Zareh. Microchimica Acta. 124(3-4) (1996) 227.

[11] A. S. Ahmad, M. D. Hoda N, M. Ahmad, F. Islam and S. Z. Qureshi. Journal of Analytical Chemistry. 61(9) (2006) 870.

[12] A. Fawzy. El-Yazbi, H. H. Abdine and R. A. Shaalan. Journal of Pharmaceutical and Biomedical Analysis. 19(6) (1996) 819.

[13] M. M. Ayad, M. M. El-Henawee, H. E. Abdellatef, H. M. El-Sayed. Alexandria Journal of Pharmaceutical Sciences. 9(2) (2005) 157.

[14] Khalifa Abulghasem El-Aroud, Adel Mohamed Abushoffa and Hisham Ezzat Abdellatef. Chem. Pharm. Bul 55(3) (2007) 364.

15] Analycicat Methods Committee, 1987. Recommendation for the definition, estimation and use of the detection limi

N N Malyst, 116(4) 387. 